\title{
Lightly Reinforced Concrete Wall Systems in India: Revisiting the Seismic Design Basis
}

\author{
S. Krishnachandran ${ }^{1}$ (1) Dixon David $^{2}$
}

Received: 11 November 2019/ Accepted: 12 October 2020/Published online: 28 October 2020

(C) The Institution of Engineers (India) 2020

\begin{abstract}
Indian construction industry, especially in the past few years, is evolving through a phase of transition towards modern innovative construction methods. Constraints in land utilization and challenges in the real estate industry resulted in finding ways for more effective space utilization leading to the change of focus from horizontally distributed to vertically distributed structures including tall buildings. Also, large-scale residential projects are being established involving mass affordable housing schemes. Under these circumstances, prominence is being given to the timely execution of projects and this marked the advent of innovative technologies in India. The use of tunnel form construction and aluminium formwork-based concrete construction systems in projects, especially residential buildings, has paved way for distributed monolithic reinforced concrete walls as the principal structural system. International codes have identified the benefits of using such systems under seismic actions with respect to the structural redundancy and overstrength achieved. These considerations have also been positively utilized by the codal provisions by allowing the design of these systems with less stringent detailing requirements and providing behaviour factors equivalent to ductile systems, or by reducing the seismic demand thus making the design of these systems more economic. Under mass affordable housing schemes, a reduction in the construction cost could achieve significant economic savings. In this context, this
\end{abstract}

\footnotetext{
$\triangle$ S. Krishnachandran

krishnchandran@gmail.com

Dixon David

dixondavid100@gmail.com

1 Institution of Engineers, Kolkata, India

2 Senior Engineer, SSIDC, Chennai, India
}

paper looks at the advent of new construction practices in India resulting in lightly reinforced monolithic distributed wall systems, the specific advantages of these systems under seismic actions and how international standards adequately take advantage of the structural redundancy and overstrength offered by these systems.

Keywords Large lightly reinforced concrete walls . Monolithic construction in India $\cdot$ Seismic design

\section{Introduction}

The choice of structural system is driven by not only the design actions but also the construction typology and the economic conditions of a region. An economy with labour costs exceeding material costs will have distributed lateral systems including multiple shear walls (e.g., Chile), and hence the redundancy achieved is much higher than framed structures [1]. Similarly, an economy dominated by material costs could rely more on framed structure typologies with large open spaces. Hence, the design guidelines of a particular region should adequately reflect the impact of the construction practice, favourable or unfavourable, to ensure proper design methods. The focus given for the fast completion of projects has led to the Indian construction industry adopting the practice of monolithic lightly reinforced wall constructions, viz. modular tunnel form construction [2, 5], monolithic concrete formwork systems using aluminium formwork [3, 5], plastic aluminium formwork, precast sandwich panel systems, precast concrete construction systems [4] and light-gauge steel structural systems. The Building Materials \& Technology Promotion Council (BMTPC) has considered the aforementioned systems as emerging technologies for mass 
housing construction projects [6]. For large-scale housing projects, these systems are being adopted instead of the conventional framed construction types for multi-storied residential buildings.

These technologies are particularly effective in projects where repeated modular construction is employed such as residential blocks, hotels, educational institutions and student accommodation. However, the effects of resorting to these new construction typologies and whether they could be included under the conventional structural load-resisting systems have not been properly addressed in the Indian design guidelines. Hence, this paper looks at understanding where this structural system could be placed in terms of expected seismic behaviour, whether these could be categorized under the lateral load-resisting systems per the Indian seismic design guidelines, the merits and limitations of using such systems by numerical studies and reviewing the international seismic design guidelines and practices.

\section{Residential Building Layout in India-Evolution from Building Frame System to System of Large Lightly Reinforced Structural Walls}

The conventionally adopted reinforced concrete (RC) structural systems for residential building layouts in India were typically building frame systems (medium- to highrise buildings) or moment-resisting frame systems. Building frame refers to the system where shear walls take majority of the lateral load and frame elements carry the gravity loads. In the recent past, the arrival of systems that can be categorized as large lightly reinforced concrete wall systems by EC8 (tunnel form construction and aluminium formwork technology) for low- to medium-rise structures has brought a framing system consisting of load-bearing walls and solid slabs ideally suited for residential apartments. International guidelines [7] and International guidelines, existing research and experimental works $[8,9]$ suggest acceptable seismic behaviour for large lightly reinforced wall systems due to the increased wall density, overstrength and the presence of adequate load path redundancy. However, the existing seismic design guidelines in India categorize building frame systems under structural wall systems consisting of both ordinary RC structural walls and ductile RC structural walls with the design of former inadmissible in seismic zones 3, 4 and 5 [10]. In contrast, international guidelines [7] warrant using the same response modification factor for lightly reinforced wall systems as that of ductile shear walls for medium levels of ductility demand (Table 1) owing to their elastic overstrength. In addition, few guidelines [11] warrant reducing the seismic demand for these structures due to the improved structural redundancy resulting from increased wall density. Hence, proper use of this structural system under demand levels requiring medium ductility response, especially seismic zone 3 , could lead the way to economic design of this structural system which could lead to huge cost savings involving mass housing projects which is of practical relevance from the perspective of 'Global Housing Technology Challenge' in India.

\section{Distributed Reinforced Concrete Structural Wall Systems: Lateral Load Response and Design Perspective}

Load path redundancy refers to the multiple ways in which a structure redistributes the loads previously carried by a load path which currently is ineffectual. A structural member is considered load-path redundant if sufficient alternative load paths are determined to exist. Typical structural systems in Chile adopt building frame systems with shorter spans and multiple structural walls [1]. Thus, configurations with alternate load paths and sufficient redundancy are achieved owing to the ease of construction possible due to relatively cheap labour. On the contrary, the cost of labour in the USA is significant resulting in building configurations with comparatively reduced labour including reduced number of structural walls (mainly service core walls) and relatively larger framing spans [1]. The recent trend of using distributed RC structural wall systems in India is driven by the savings achieved through time and labour. In these structural systems represented by aluminium formwork or tunnel form construction, majority of the vertical load and lateral load is carried by the walls and a typical framing layout indicates the presence of adequate load path redundancy for this structural system as shown in the layout (Fig. 1).

Structural systems containing load-bearing RC structural walls represent a typology which is widely being used in mass public housing projects. Such building structures characterized by a wall thickness of $150-250 \mathrm{~mm}$ and lesser percentage values of steel reinforcement have shown excellent strength resources even against strong earthquake ground motions derived from their structural overstrength [9, 13, 14]. However, few experimental and analytical studies have been undertaken till now to study the seismic performance of structural systems with large lightly reinforced concrete walls [9]. Distributed lateral systems consisting of RC bearing walls have been incorporated as a structural system by the Eurocode [7] as well as the Chile seismic design code [11]. While the Chile design code considers it as a bearing wall system, the European guidelines include a specific category called large lightly reinforced structural wall system (Table 1). However, the approach by which both these codes utilize the redundancy 
Table 1 Structural systems as per international guidelines

\begin{tabular}{|c|c|c|c|}
\hline ASCE 7-10 [12] & Chile code [11] & European guidelines [7] & Indian standards [10] \\
\hline $\begin{array}{l}\text { Bearing wall systems } \\
\text { Rfactor }(\text { Special }=5, \text { Intermediate }=4)\end{array}$ & $\begin{array}{l}\text { Shear wall and other braced } \\
\text { systems }^{\mathrm{a}}\end{array}$ & Frame system & Moment frame systems \\
\hline $\begin{array}{l}\text { Building frame systems } \\
R \text { factor }(\text { Special }=6, \text { Intermediate }=5)\end{array}$ & $\begin{array}{l}\text { Space moment-resisting frame } \\
\text { system }^{\mathrm{a}}\end{array}$ & Dual system (frame or wall equivalent) & Braced frame systems \\
\hline Moment resisting frame systems & Dual systems $^{\mathrm{a}}$ & $\begin{array}{l}\text { Ductile wall system(coupled or } \\
\quad \text { uncoupled) } \\
R \text { factor } \\
\text { (Ductile class medium-3, Ductile Class } \\
\text { High-4.5) }\end{array}$ & $\begin{array}{l}\text { Structural wall systems } \\
R \text { factor (ordinary-3, } \\
\text { ductile-4) }\end{array}$ \\
\hline $\begin{array}{l}\text { Dual systems with special moment } \\
\text { resisting frames }\end{array}$ & & $\begin{array}{l}\text { System of large lightly reinforced walls } \\
R \text { factor } \\
\text { (ductile class medium-3) }\end{array}$ & Dual systems \\
\hline $\begin{array}{l}\text { Dual systems with intermediate moment } \\
\text { frames }\end{array}$ & & Inverted pendulum system & $\begin{array}{l}\text { Flat slab-structural wall } \\
\text { systems }\end{array}$ \\
\hline Shear wall-frame interactive system & & Torsionally flexible system & \\
\hline
\end{tabular}

${ }^{\mathrm{a}}$ Response modification factors dependent on the time period

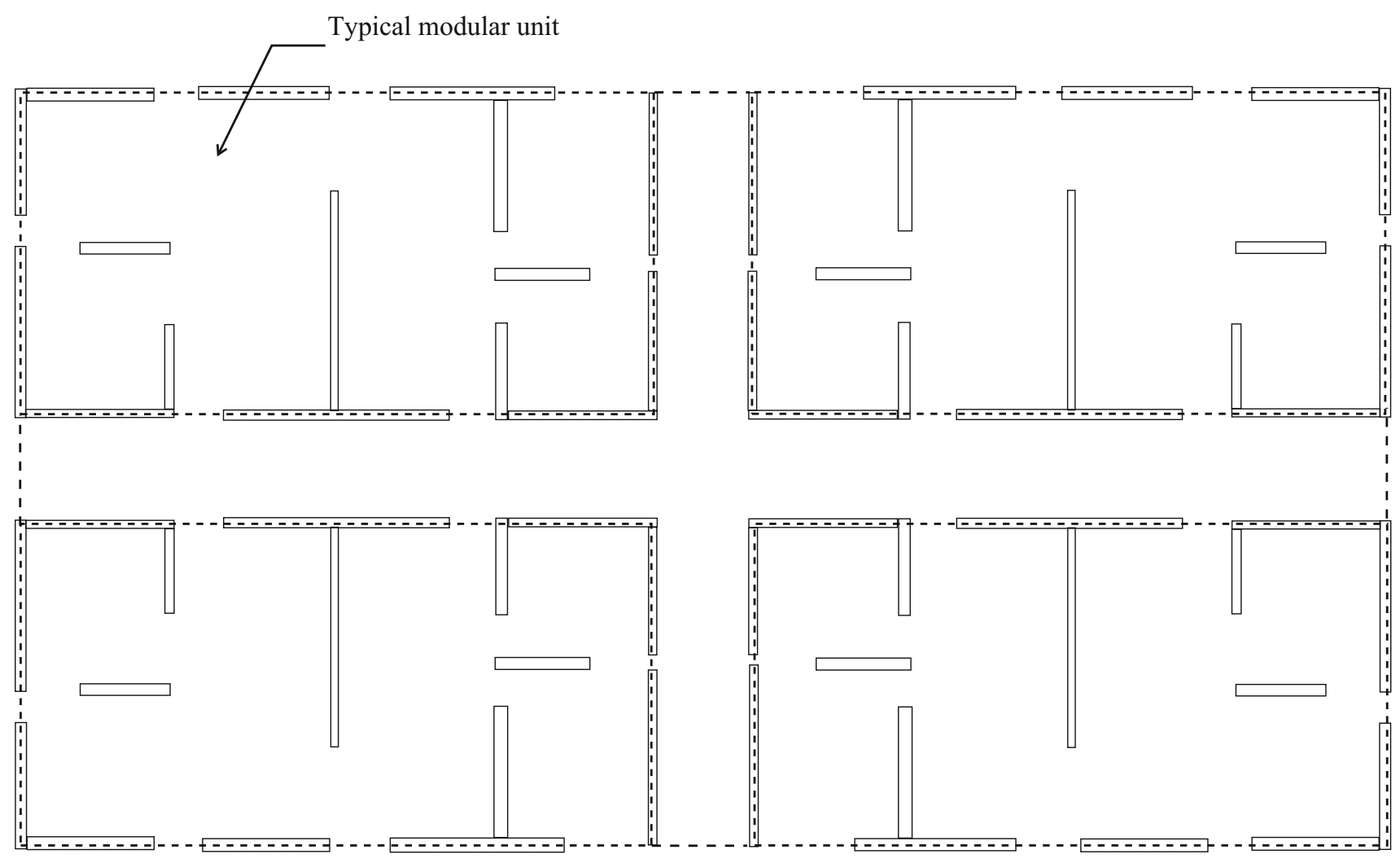

Fig. 1 Lightly reinforced concrete wall system in India: typical floor layout

and elastic overstrength of these systems into design practice is different.

EC 8 [7] provides special design provisions for structural systems consisting of large lightly reinforced walls based on past earthquakes and experimental results. As per the provisions of EC 8 [7], such a system should have at least two walls in each horizontal direction for redundancy and torsional resistance that meet the criteria for large lightly reinforced walls. These walls should resist at least $65 \%$ of the seismic base shear in each horizontal direction 


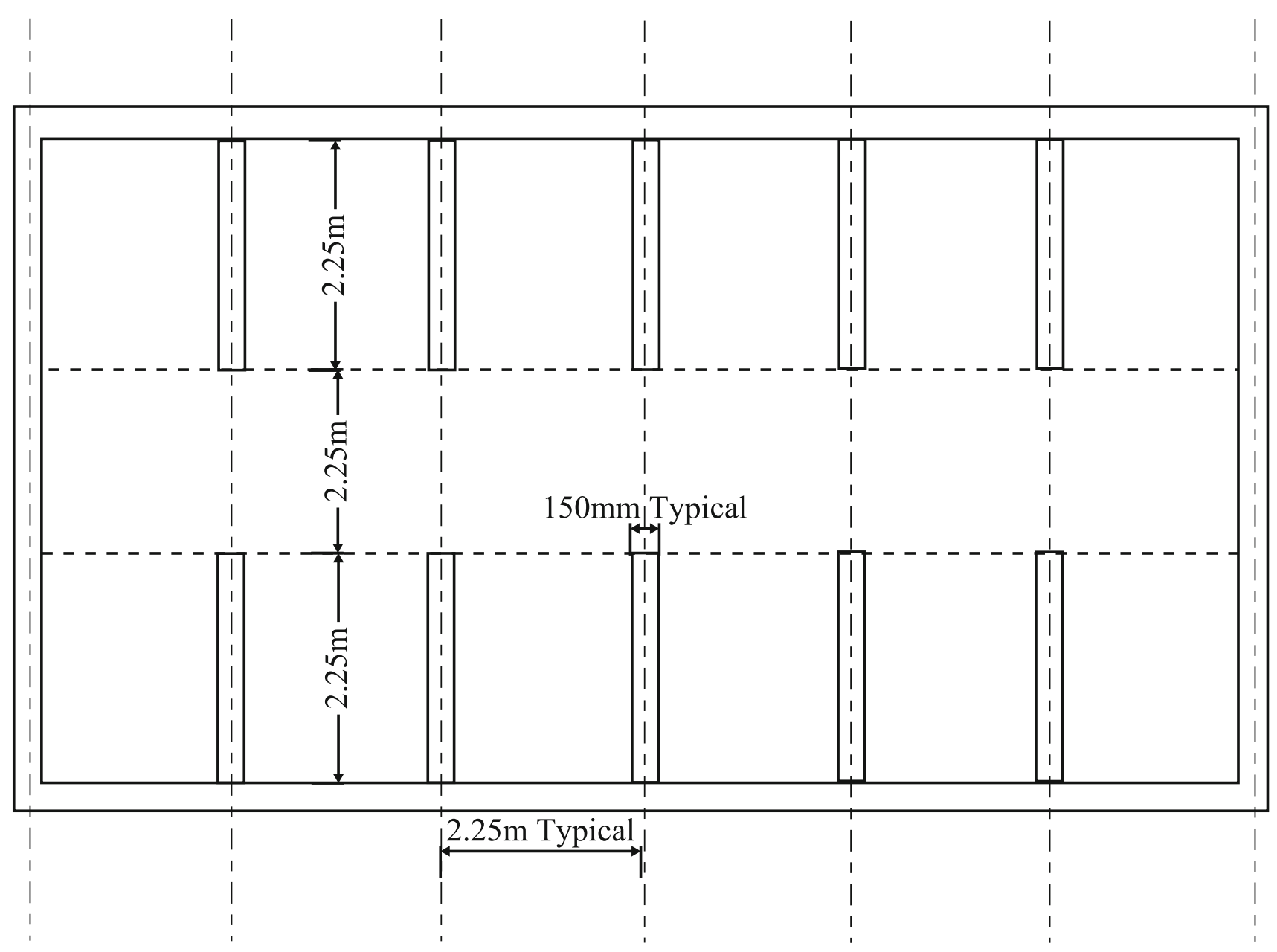

Fig. 2 Floor plan of the building (numerical model)

and support together at least $20 \%$ of the total gravity load. The building should also have a fundamental period less than or equal to $0.5 \mathrm{~s}$ in each direction with all elements fixed against rotation at the base. For the typical floor layouts as shown in Fig. 1, the reinforced structural walls resist the total lateral forces in both $\mathrm{x}$ - and $\mathrm{y}$-directions and the time period comes less than $0.5 \mathrm{~s}$ for medium-rise buildings.

If the structural system meets the above conditions, the walls are categorized as large lightly reinforced walls and

Table 2 Modal analysis results

\begin{tabular}{ll}
\hline Wall ratio $(\%)$ & Fundamental time period (s) \\
\hline 1.5 & 0.82 \\
3 & 0.50 \\
3.75 & 0.44 \\
4.5 & 0.38 \\
\hline
\end{tabular}

are permitted to be designed and detailed economically using the provisions set in EC8 [7]. This includes a basic response reduction factor equal to that of structural wall systems with ductile walls designed and detailed according to the more severe requirements for ductile walls belonging to the category of Ductility Class Medium (DCM). This correlation for large lightly reinforced wall systems comes from the perspective of energy dissipation mechanism. Conventional structural systems sustain seismic demands by dissipation of kinetic energy through hysteresis in plastic hinges. Hence, special detailing provisions are incorporated to ensure ductile behaviour in these zones. However, in large lightly reinforced concrete wall systems, energy dissipation is attained by converting a part of the seismic energy into potential energy of the masses by partial lifting and dissipation of this energy through the rocking of the walls [15]. Reinforced concrete structural walls with large plan dimensions are expected to have restricted inelasticity under seismic actions since the walls 


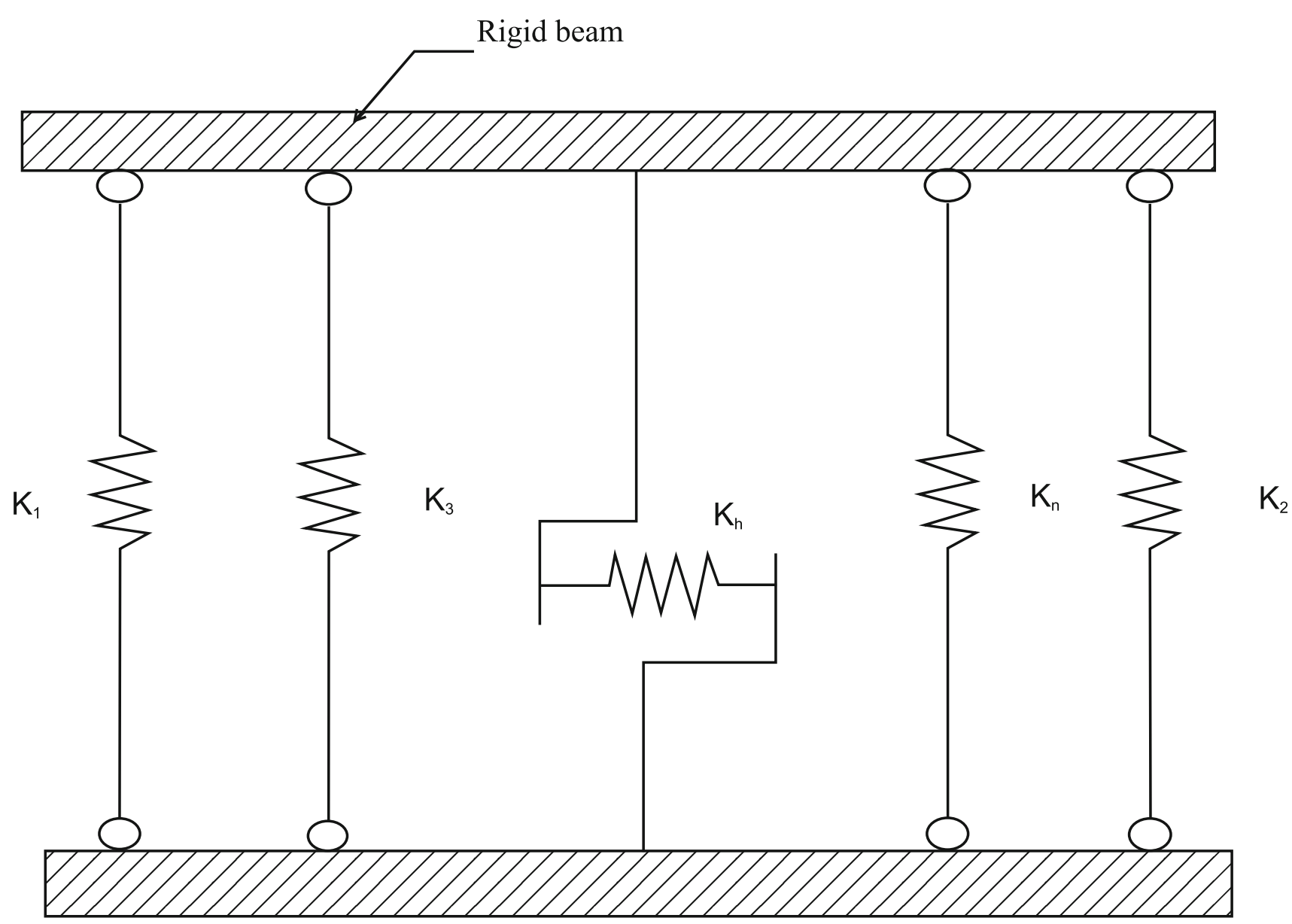

Fig. 3 Multiple vertical line element model [27]

Fig. 4 Relative rotation in MVLEM [27]

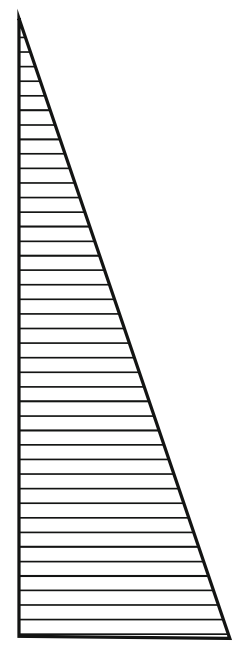

Moment

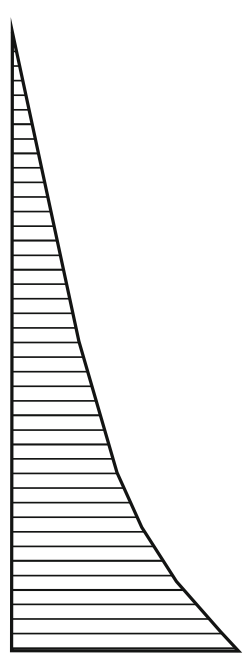

Curvature

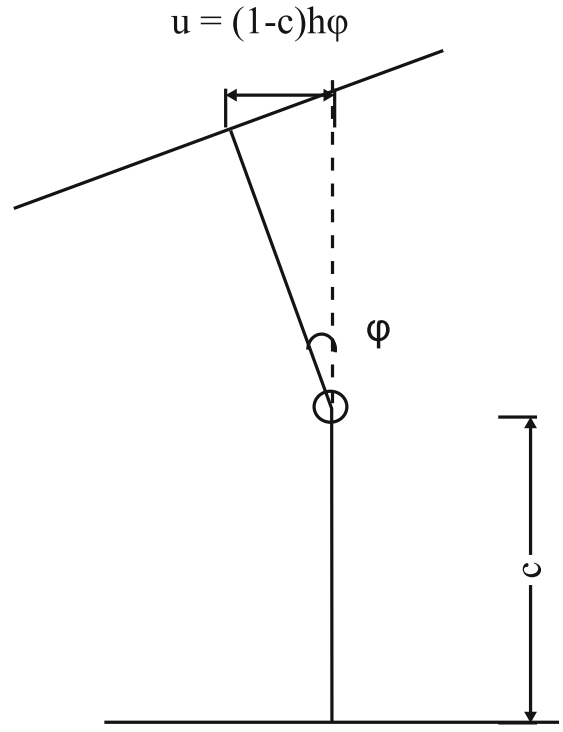

are monolithically interconnected along transverse and longitudinal directions, and hence, they do not undergo plastic hinging with respect to the base [16]. The failure mechanism expected is through a combination of partial uplift of the wall with respect to the ground and rotation of the rigid macroblocks formed through yield lines of 
cracking. This rocking mechanism of the macroblocks results in radiation damping effective for reducing highfrequency components of the input motion [16]. However, shear forces obtained from the analysis are scaled to make sure that flexural yielding occurs before the limit state of shear is reached. This is because for lightly reinforced squat shear walls, the deformation capacity was observed to be restricted by shear failure [13].

In addition, the additional axial forces generated due to the rocking of walls should be considered in the analysis of the structure which shall be taken as $50 \%$ of the axial force in the absence of exact calculations [16]. However, under certain situations including cases of walls with length less than $4 \mathrm{~m}$ or two-thirds of the total height in buildings with height less than $6 \mathrm{~m}$, the lightly reinforced walls are prescribed to be designed and detailed according to the requirements for ductile walls. The monolithic formworkbased constructions in India are categorized as shear wall systems [6] with the maximum spacing between crosswalls limited to one and half times the floor height if the walls are supported on two edges and two times the floor height if supported on all four walls. Hence, the maximum cross-wall spacing or the length of the main walls in a typical building with $3 \mathrm{~m}$ floor height will be restricted to $4.5 \mathrm{~m}$ and $6 \mathrm{~m}$ as per the above conditions. Hence, majority of the monolithic concrete walls could come under the category of lightly reinforced wall systems without ductile detailing requirements as per the above definitions.

For structural systems in Chile, the conventional practice is to employ buildings with short floor spans and multiple load-bearing walls providing both gravity and lateral force resistance. As a result, typical Chilean buildings have highly redundant configurations. This practice likely contributed to the ability of many buildings to withstand severe damage without collapse. As a consequence of this redundancy, and past experience with typical building configurations, requirements for ductile detailing in Chile are relaxed relative to US requirements [1].

The Chile seismic design code considers the redundancy of lightly reinforced wall systems by reducing the seismic demand acting on the structure [11]. The code introduces an additional reduction in the design forces for buildings with lateral load-resisting systems consisting of either RC walls, RC walls with frames, or RC walls in with reinforced masonry walls by introducing a reduction factor [11],

$f=1.25-0.5 q$

where $q$ is the fraction of the base shear resisted by the reinforced concrete walls in the lower half of the building $(0.5<q<1)$. Thus, for typical buildings consisting of RC walls entirely, the maximum base shear coefficient is reduced to $75 \%$.

\section{Seismic Performance of Large Lightly Reinforced Wall Systems}

Reinforced concrete buildings with large lightly reinforced structural walls have shown good behaviour during seismic events, even if the walls were designed as gravity loadresisting elements with low reinforcement as per the current design provisions [15]. Existing literature indicates acceptable performance of such buildings in several earthquakes including Chile (1985), Skopje (1963), San Fernando (1971), etc. [13, 15]. The presence of large shear walls has ensured good seismic performance and the ability to sustain seismic actions with minor damages in many cases which contradict brittle shear failure for nonductile walls. Compared to framed construction types, shear wall structural systems result in less story drifts, restrict the formation of soft storey mechanism and hence limit damage propagation for the structural elements. Few experimental works and analytical studies [8, 17-21] have been carried out till date for characterizing the behaviour of lightly reinforced $\mathrm{RC}$ walls. Large shear walls also prevent the occurrence of soft storey mechanism which is considered as detrimental to good seismic performance. Moreover, these analyses have shown that the structural performances under seismic actions are function of the wall density, which is defined as the walls-to-floor surface ratio; in particular, buildings with walls density of $3-4 \%$ have shown a good performance [9].

These large walls rely on their geometry rather than the strength and hysteretic dissipation capacity of reinforcement to resist seismic actions [16]. In this system, flexural overstrength is intentionally avoided. And hence, it is provided with special design and detailing rules which result in much less reinforcement than for ductile walls, under the condition that these are used in a lateral forceresisting system consisting mainly of such typology of walls. The defining feature of this system is the wall density and the structural overstrength achieved due to this. In regions of low to moderate seismic intensity, it has been demonstrated that minimum reinforcement provides enough overstrength for the wall resulting in less stringent detailing and conservative response reduction factors. Hence, in cases with low to moderate seismic demand for low-rise structures, the flexural resistance provided by minimum reinforcement was observed to be adequate and higher than the code requirements with the structure remaining elastic [21]. Previous research indicates that the number of structural members undergoing yielding decreases as the shear wall ratio increases, even under 
Fig. 5 Idealized floor plan for OpenSees model

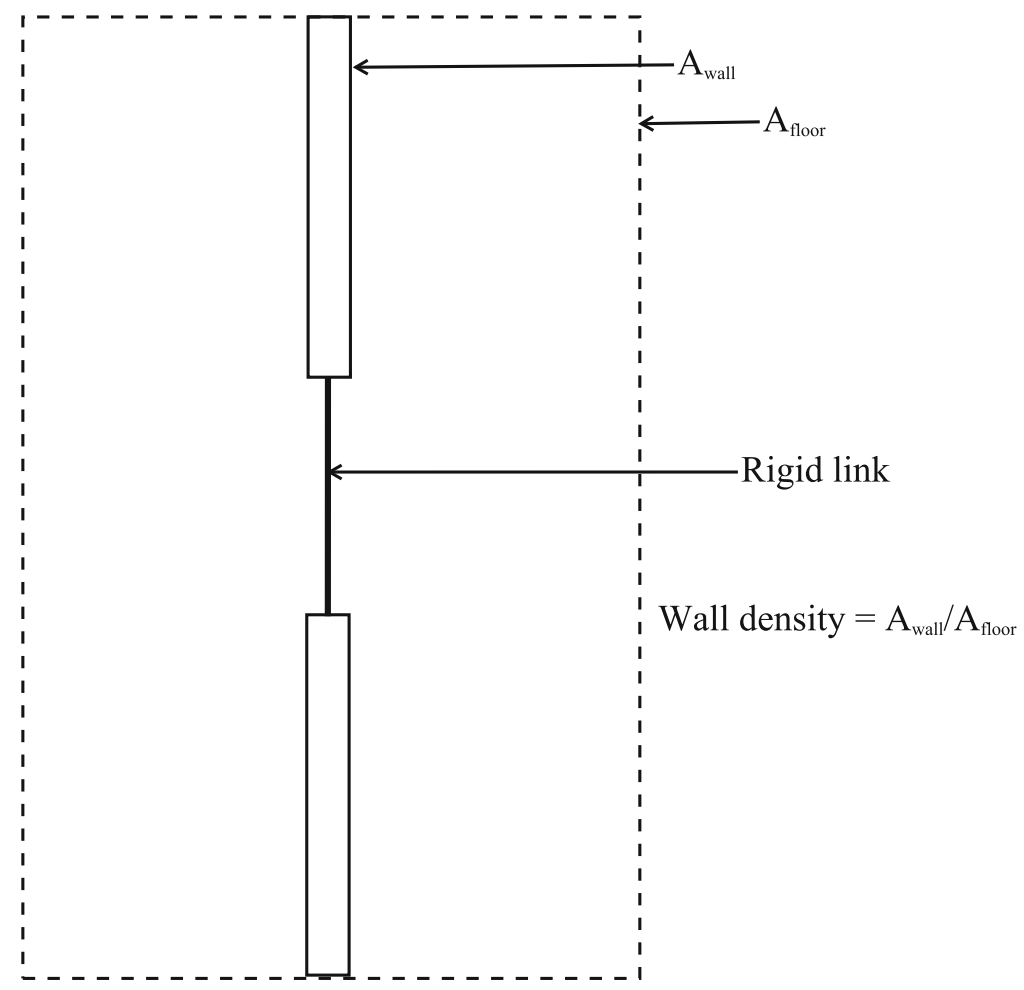

$\mathrm{A}_{\text {wall }}$ : Cross sectional area of walls at a particular storey $\mathrm{A}_{\text {floor: }}$ : Total area of the floor at a particular storey

Table 4 Results (ultimate load and yield load)

Table 3 Overstrength of lightly reinforced wall systems

\begin{tabular}{lll}
\hline Wall density/longitudinal reinforcement percentage & $0.25 \%$ & $0.12 \%$ \\
\hline $\begin{array}{l}\text { Total overstrength due to increase in wall density } \\
\text { (.5\% with reference to }\end{array}$ \\
$3 \%$ & 6.57 & 4.80 \\
$3.75 \%$ & 7.50 & 5.28 \\
$4.50 \%$ & 8.38 & 5.63 \\
Elastic overstrength & & \\
$3 \%$ & 3.15 & 2.30 \\
$3.75 \%$ & 3.52 & 2.48 \\
$4.50 \%$ & 3.83 & 2.58 \\
Redundancy factor & & \\
$3 \%$ & 2.08 & 2.08 \\
$3.75 \%$ & 2.13 & 2.13 \\
$4.50 \%$ & 2.19 & 2.18 \\
\hline
\end{tabular}

strong ground motions [22]. This effect is predominant when the wall ratio goes beyond $1.5 \%$ indicating that there is higher elastic overstrength for structures with wall ratio greater than $1.5 \%$. Typically, structures with a wall ratio of $3-4 \%$ are shown to provide excellent performance under earthquakes. For the typical floor layout shown in Fig. 1,

\begin{tabular}{llll}
\hline $\begin{array}{l}\text { Wall density } \\
(\%)\end{array}$ & $\begin{array}{l}\text { \% Longitudinal } \\
\text { reinforcement }\end{array}$ & $\begin{array}{l}\text { Yield load } \\
(\mathrm{kN})\end{array}$ & $\begin{array}{l}\text { Ultimate load } \\
(\mathrm{kN})\end{array}$ \\
\hline 3 & 0.25 & 551 & 1737 \\
3 & 0.12 & 548 & 1264 \\
3.75 & 0.25 & 563 & 1983 \\
3.75 & 0.12 & 560 & 1390 \\
4.5 & 0.25 & 578 & 2214 \\
4.5 & 0.12 & 575 & 1484 \\
\hline
\end{tabular}

the wall ratio comes as high as $6 \%$ and the fundamental time period comes lesser than $0.5 \mathrm{~s}$ for a ten-storied structure with assumed rotational fixity at base. In addition, as the shear wall ratio increases, the roof drift and interstorey drift decrease due to the relative increase in stiffness ratio. Further, for braced frame and shear wall systems, the relative increase in strength capacity with redundancy can be higher than for RC special moment frames [23]. The overall response reduction factor is a function overstrength, redundancy and ductility. These structural systems show high elastic overstrength factors compared to other systems, low drift ratios, and the redundancy of such systems due to the multiple lines of lateral load-resisting systems is 


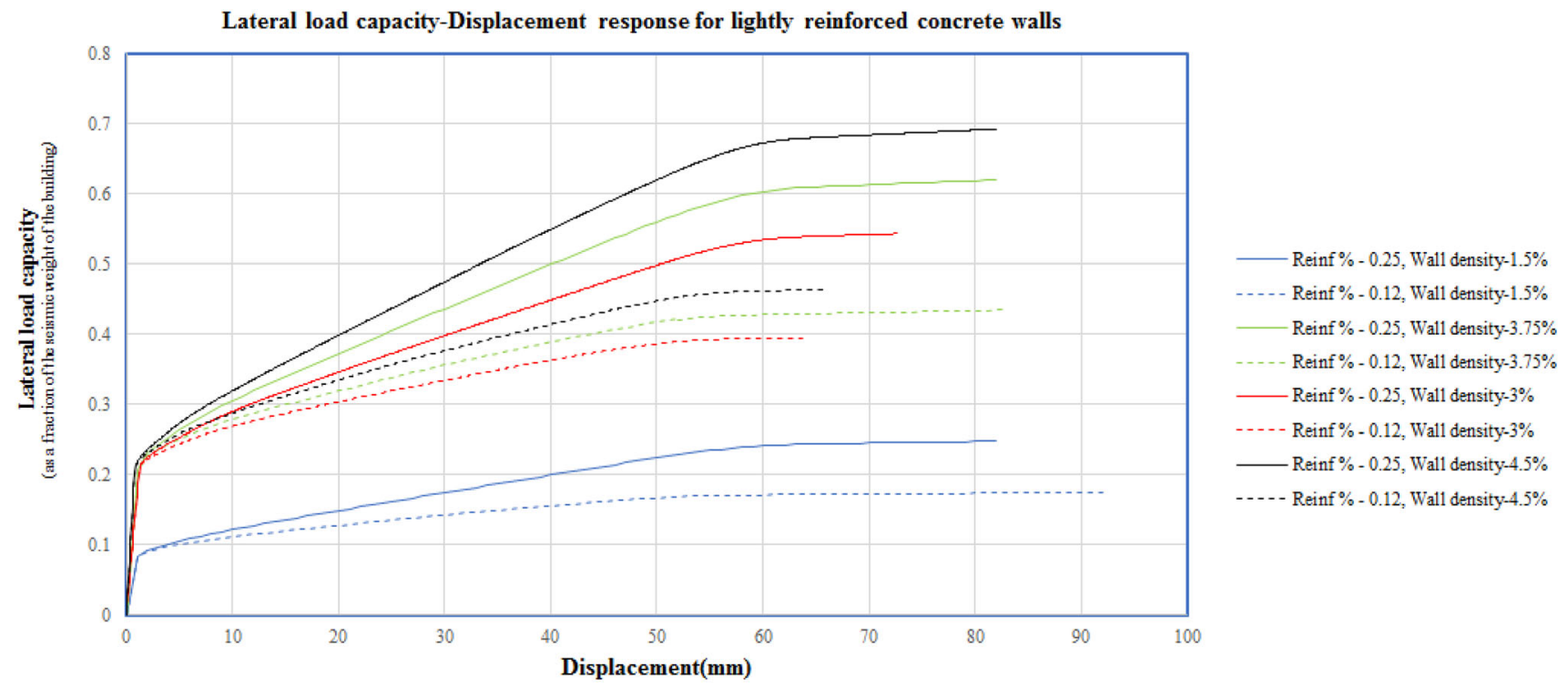

Fig. 6 Force-deformation response

Fig. 7 Idealized forcedeformation curve for lightly reinforced walls

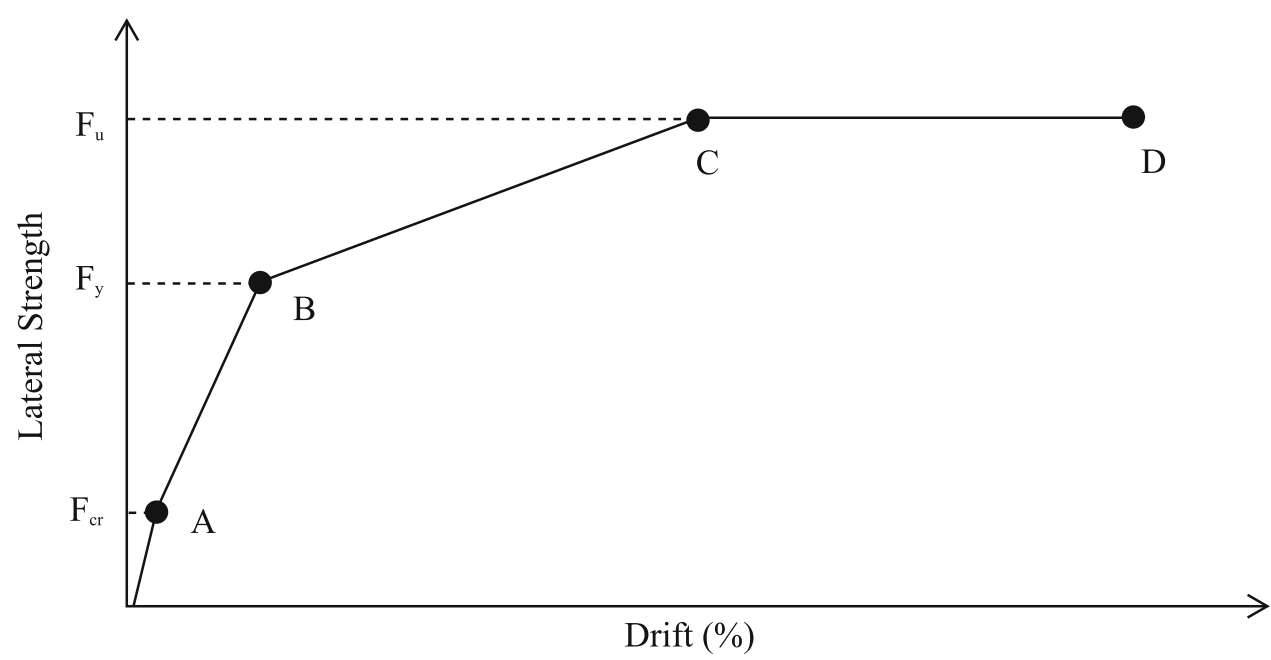

also considerably large. Adopting surplus ductility into the wrong structural system could be inappropriate, especially in regions with low to moderate seismicity with lesser displacement demands. Hence, the maximum displacement demands for stiff low- to medium-rise structures with multiple shear walls in low to moderate seismic regions can be less resulting in higher elastic overstrength for these structures. This leads detailing practices to follow the principle of achieving limited or restricted ductility to ensure satisfactory performance.

However, one critical point to be noted is that beyond the elastic overstrength of the structure, cantilevered wall structures have very little redundancy which defines a limit for the height of the building, seismic intensity levels and wall density, beyond which a small increase demand results in significant vulnerability including brittle failure modes of the structure [29]. Hence, adopting this system could be questionable in areas of high ductility demand where interplate earthquakes result in high-intensity ground shaking and significant displacement demands.

\section{Numerical Analysis}

Numerical studies were performed to evaluate the overstrength and ductility requirements of lightly reinforced wall systems. The floor plan of the idealized building used for numerical modelling (Fig. 2) was determined based on 
the floor plan of the typical aluminium formwork based construction building with large lightly reinforced structural walls (Fig. 1). The building was designed as per IS 1893 Part 1 [10], IS 13920 [24] and IS 456 [25] using the software package ETABS [31]. This structure has a wall density corresponding to $3.75 \%$, where wall density is defined as the ratio of total area of walls to the total plan area of the structure at a particular story. The influence of the flanges has not been taken into consideration in the model. Dead load corresponding to $4 \mathrm{kN} / \mathrm{m}^{2}$, superimposed dead load of $2 \mathrm{kN} / \mathrm{m}^{2}$ and live load of $4 \mathrm{kN} / \mathrm{m}^{2}$ were assumed for the preliminary design. For seismic design, the structure was considered to be in a Zone 3 corresponding to moderate seismic intensity and a zone factor of 0.16 . The grade of concrete used was $40 \mathrm{MPa}$, and the yield strength of steel used was $500 \mathrm{MPa}$. The walls were modelled as thin shell elements, slabs were modelled as membrane elements and a rigid diaphragm assumption was used in the design. The results indicated that all the walls above the ground storey were safe with a thickness of $150 \mathrm{~mm}$ with minimum percentage of longitudinal steel reinforcement $(0.12 \%$ corresponding to nonductile walls) and the ground storey walls at $0.23 \%$. Based on these results, parametric studies were carried out using OpenSees [26] to evaluate the seismic performance of lightly reinforced wall systems for reinforcement ratios.

1. $0.12 \%-$ Corresponding to nonductile shear walls [24].

2. $0.25 \%$ - Corresponding to ductile shear walls [25].

The thickness of the wall $(150 \mathrm{~mm})$ and the number of stories (6) were kept at a constant value since an economic mass housing project in India currently has buildings with number of stories in the range of 5-10. The element used for modelling the walls was MVLEM (Multiple Vertical Line Element Model) [27], which has been successfully used for lightly reinforced walls [21, 28, 29]. In MVLEM (Fig. 3), several vertical springs are connected by rigid beams at the top and bottom level. The walls could be subdivided into desired number of vertical spring elements $(\mathrm{K} 1 \ldots \mathrm{Kn})$ to capture the axial stiffness. Horizontal spring with stiffness $K_{h}$ captures the shear behaviour. At a height equal to ' $c$ ' times the height of the wall from bottom, the rotation of the wall is assumed to take place (Fig. 4). The value of ch represents the distance between the centroid of the curvature distribution curve and the base and could vary from 0 to 1 depending on the curvature profile of the wall (with a value of 0.5 for uniform moment distribution and 0.3 for triangular distribution). However, in the absence of exact data, an average value of ' 0.4 ' is considered to simulate the rotational behaviour reasonably well [30]. Axial force on the walls was taken from the ETABS model and applied on the walls based on the tributary area. The structural system was idealized as shown in Fig. 5 for modelling in OpenSees [21], and the modal analysis results for different cases are shown in Table 2. Further, nonlinear pushover analyses were performed for six different cases (three different wall densities and two different longitudinal reinforcement ratios) by varying the wall density and percentage of longitudinal reinforcement to assess the seismic performance.

\section{Results and Discussion}

The capacity curves for the buildings under consideration are plotted in Fig. 6, and the results are presented as elastic overstrength, redundancy factor and total overstrength (Table 3). The idealized force-deformation response of a lightly reinforced wall system is shown in Fig. 7 [32]. Slender lightly reinforced walls undergo flexural rocking response, and as shown in Fig. 7, the four points denote cracking (A), yielding (B), peak load (C) and ultimate displacement (D) corresponding to crushing at the compressed edge and failure happens by crushing of concrete at the extreme compressed edge. Elastic overstrength is obtained as the ratio of ultimate load to yield load for the buildings under consideration. The yield load was calculated based on energy balance approach, and the ultimate load and yield load for each structure are shown in Table 4 . Further, total overstrength is defined as the overstrength of the structure with reference to the yield load for the structure with $1.5 \%$ wall density. Alternatively, this can be considered as the ratio of the ultimate load of the system to the load corresponding to the yielding of the first wall/first set of walls. This is different from the elastic overstrength calculated in Table 4 fundamentally due to the idealization chosen in modelling the structure. As a part of the idealization adopted for modelling in OpenSees (Fig. 5), a system with multiple walls is modelled as a single unit by varying the wall ratio and hence the yield load of the unit corresponds to the simultaneous yielding of all the walls. Hence, to obtain the actual overstrength of the system, this has to be compared with the load corresponding to the yielding of the first wall. Due to the symmetry of the structure, a system consisting of four walls $(1.5 \%$ wall ratio) is assumed to have all the walls reaching the yield load simultaneously and hence the total overstrength is calculated with reference to the yielding of this reference structure with a wall density of $1.5 \%$. Further, Table 3 denotes the redundancy factor which is the ratio of total overstrength to elastic overstrength. The invariance of this parameter with respect to the percentage of reinforcement (Table 3) indicates its sole dependence on the geometry of the system.

From Table 3, it is clear that with an increase in wall density, there is a corresponding increase in the 
overstrength of the system. A total overstrength factor ranging from 6.6 to 8.4 was obtained with a reinforcement percentage of $0.25 \%$ and 4.8 to 5.6 for a reinforcement percentage of $0.12 \%$, which is significantly higher than the current response modification factors of 4 and 3 for ductile walls and nonductile walls, respectively. This further reinforces the fact that for large lightly reinforced $\mathrm{RC}$ walls, the response modification factor should be represented as a function of the wall density. These results also indicate that the use of details corresponding to restricted ductility with reduced minimum percentage of steel could be adopted in low to moderate seismic zones which could result in considerable savings in terms of both energy impact and economy. In high seismic zones where increased ductility demands are possible, further studies are required for system of large lightly reinforced walls to check whether it requires the existing detailing requirements for special walls. However, in both these cases, the response modification factor is something which requires a revisit so that the concept of wall density is adequately captured and the system is positively benefitted from the effects of the same.

\section{Conclusions}

Design conservatism was an aspect which negatively affected a structural design from the perspective of economy only. However, in the present scenario, striking a balance between design conservatism and energy impact is essential from the perspective of environmental sustainability as well. Code-ensured design conservatism is essential for a structure, considering the wide range of uncertainties existing in each stage of the design process. Overstrength factors including material overstrength, system overstrength and redundancy effects bring in adequate design conservatism; however, the energy impact due to this could be significant. Hence, structural engineers should give due consideration to optimize design without compromising with the stability and longevity of the structure, thereby restricting conservatism which is beyond the safe requirement for the structure. In this context, the advent of new construction typology in India has a possibility of being categorized as large lightly reinforced concrete wall system which could result in considerable savings in energy and economy without compromising safety of the system. Existing literature suggests that detailing these systems to limited or restricted ductility in areas of low to moderate seismicity could result in satisfactory seismic performance. Referring to the design codes and practices of higher seismic regions and implementing these in low seismic regions can be conservative in some aspects and inappropriate in the other. Hence, if the categorization of such system into 'large lightly reinforced wall systems' is supported with further experimental and analytical studies, there is a positive effect of economizing the structural system either by detailing these for 'limited/restricted ductility' bringing in less stringent seismic detailing requirements for walls coming under this category under low to medium levels of ductility demand (particularly Zone 2 and Zone 3 as per Indian seismic zonation) or reducing their design forces by choosing appropriate response reduction factors that also accounts for the inherent redundancy present in the system. In the modern scenario of increasing housing demand and innovations in infrastructure sector, such a small change could bring in huge savings for the economy of the nation, particularly with respect to affordable mass housing projects.

\section{References}

1. NIST GCR 12-917-18, Comparison of U.S. and Chilean Building Code Requirements and Seismic Design Practice, NEHRP Consultants Joint Venture (2010)

2. E. Kalkan, S.B. Yuksel, Pros and cons of multistory RC tunnelform (box-type) buildings. Struct. Des. Tall Spec. Build. 17, 601-617 (2007). https://doi.org/10.1002/tal.368

3. Mivan Formwork Products, Products \& Services, MFE Formwork Technologies, www.mfeformwork.com

4. V.P.S. Nihar, R. Basu, A. Sawhney, H. Vikram, G. Lodha, Implementation of precast technology in India opportunities and challenges. Procedia Eng. 196, 144-151 (2017)

5. Use of innovative technologies and materials in construction, CPWD, Ministry of Housing \& Urban Affairs (2019)

6. BMTPC (Building Materials and Technology Promotion Council), Compendium of Prospective Emerging Technologies for Mass Housing, 3rd edition (2018)

7. Eurocode 8. 2004, Design of Structures for Earthquake Resistance, Part 1: General Rules, Seismic Actions and Rules for Buildings, EN1998-1 (2004)

8. K. Orakcal, L.M. Massone, W. Wallace, Shear strength of lightly reinforced wall piers and spandrels. ACI Struct. J. 106(4), 455-465 (2009)

9. M. Pecce, F.A. Bibbo, F. Ceroni, Seismic behavior of RC buildings with large lightly reinforced walls. in Proceedings of 15th World Conference on Earthquake Engineering, September 24-28, Lisbon, Portugal (2012)

10. IS 1893 (Part1), Indian Standard Criteria for Earthquake Resistant Design Structures (fifth Revision), Bureau of Indian Standards (2016)

11. Engineers Association of Chile, 2010, Chilean Standard NCh433.Of96: Seismic Design of Buildings Rev (2009)

12. ASCE. Minimum Design Loads for Buildings and Other Structures, ASCE/SEI Standard 7-10 (2010)

13. C. Greifenhagen, Seismic behavior of lightly reinforced concrete squat shear walls. Thesis (2006)

14. C. Balkaya, E. Kalkan, Seismic Vulnerability, Behavior and Design of Tunnel form Building Structures. Eng. Struct. 26, 2081-2099 (2004)

15. M.L. Moretti, Earthquake design of buildings with large lightly reinforced concrete walls, in Proceedings of Second European Conference on Earthquake Engineering (2017) 
16. M.N. Fardis, Seismic Design, Assessment and Retrofitting of Concrete Buildings Based on EN-Eurocode8 (Springer, Dordrecht, 2009)

17. A. Ghobarah, Dynamic response of lightly reinforced concrete walls, in Proceedings of Thirteenth World Conference on Earthquake Engineering, no. 1090 (2004)

18. S.J. Menegon, J.L. Wilson, N.T.K. Lam, Design of reinforced concrete walls in regions of lower seismicity, in Proceedings of World Congress on Advances in Structural Engineering \& Mechanics (2017)

19. A. Wibowo, J.L. Wilson, N.T.K. Lam, E.F. Gad, Seismic performance of lightly reinforced structural walls for design purposes. Mag. Concr. Res. 65, 13 (2013)

20. D. Ugalde, D. Lopez-Garcia, Elastic overstrength of reinforced concrete shear wall buildings in Chile, in Proceedings of Sixteenth World Conference on Earthquake Engineering, no. 4560 (2017)

21. M. Fischinger, T. Isakovic, P. Kante, Seismic vulnerability evaluation of lightly reinforced walls, in Proceedings of Thirteenth World Conference on Earthquake Engineering, no. 468 (2004)

22. B. Burak, Effect of shear wall area to floor area ratio on the seismic behavior of reinforced concrete buildings. J. Struct. Eng. 139, 1928-1937 (2013)

23. A. Tena-colunga, J.A. Cortés-Benítez, Assessment of redundancy factors for the seismic design of special moment resisting reinforced concrete frames. Latin Am. J. Solids Struct. 12, 2330-2350 (2015)

24. IS 456:2000, Plain and Reinforced Concrete-Code of Practice (Fourth Revision). Bureau of Indian Standards (2016)
25. IS 13920: 2016, Ductile Design and Deatiling of Reinforced Concrete Structures Subject to Seismic Forces-Code of Practice (First Revision). Bureau of Indian Standards (2016)

26. F. McKenna, OpenSees: a framework for earthquake engineering simulation. Comput. Sci. Eng. 13, 58-66 (2011)

27. K. Kolozvari, K. Orakcal, J.W. Wallace, Shear-flexure interaction modeling of reinforced concrete structural walls and columns under reversed cyclic loading. Pacific Earthquake Engineering Research Center, University of California, Berkeley, PEER Report No. 2015/12 (2015)

28. M. Carolina, S.K. Kunnath, Non-linear response analysis of reinforced concrete shear walls using multi-springs macro-models, in NCEE 2014-10th U.S. National Conference on Earthquake Engineering: Frontiers of Earthquake Engineering (2014)

29. A. Barnes, A collapse study of a lightly reinforced concrete shear wall building during the February 22, 2011 Christchurch earthquake, Electronic Theses and Dissertations (ETDs). University of British Columbia (2014)

30. W. Tian, T. Lan, Y. Xiao, Y. Yang, Macro-modeling of reinforced concrete structural walls: state-of-the-art. J. Earthq. Eng. 21(4), 652-678 (2017)

31. ETABS Software Version 15, Computer and Structures, Inc. Berkeley, California, USA

32. A. Wibowo, J.L. Wilson, N.T.K. Lam, E.F. Gad, Seismic performance of lightly reinforced structural walls for design purposes. Mag. Concr. Res. 65(13), 809-828 (2013)

Publisher's Note Springer Nature remains neutral with regard to jurisdictional claims in published maps and institutional affiliations. 